\title{
Analisis Postur Kerja Karyawan Kantor Menggunakan Rapid Office Strain Assesment (ROSA)
}

\author{
Zayyinul Hayati Zen, Andre Habiyoga, Denny Astrie Anggraini \\ Program Studi Teknik Industri, Universitas Muhammadiyah Riau \\ Jl. Tuanku Tambusai ujung, Pekanbaru \\ e-mail:eza_ab@yahoo.com
}

\begin{abstract}
Abstrak
PT. Universal Tekno Reksajaya adalah perusahaan yang bergerak dibidang remanufactur, general fabrikasi dan maintenance alat berat. Perusahaan ini memiliki beberapa divisi yaitu administrasi, marketing, produksi, service, dan warehouse. Penelitian ini fokus kepada divisi yang pekerjanya bekerja di ruangan. Pekerja selalu menggunakan computer dan bekerja 8 jam/hari. Dan juga memungkinkan mereka untuk lembur sehingga menyebabkan pekerja merasakan keluhan-keluhan dalam bekerja. Penelitian awal dengan menyebarkan Standar Nordic Questionnaire (SNQ). Hasil dari kuesioner yaitu banyaknya pekerja merasakan sakit pada punggung, pinggang, nyeri bahu, leher dan tangan. Keluhan yang dirasakan oleh pekerja kantor dapat diminimalkan dengan cara mengetahui dan mengidentifikasi postur kerja pada pekerja dalam menggunakan komputer. Penelitian ini menggunakan metode Rapid office strain assessment (ROSA). ROSA merupakan salah satu metode pada office ergonomics, dimana penilaiannnya dirancang untuk mengukur resiko yang terkait dengan penggunaan komputer serta untuk menetapkan tingkat tindakan perubahan berdasarkan laporan dari ketidaknyamanan pekerja. Dengan menggunakan metode ROSA, dapat diketahui apakah postur kerja karyawan kantor PT. Universal Tekno Teksajaya Plant Pekanbaru pada saat bekerja aman atau berbahaya. Hasil penilaian postur kerja dengan ROSA ini yaitu postur kerja beresiko tinggi, pada kondisi tersebut akan menyebabkan cidera pada pekerja yang melakukan pekerjaannya secara terus-menerus dan dalam jangka waktu yang lama. Maka dari itu perlu direkomedasikan ke pihak perusahaan untuk memberikan pelatihan tentang ergonomi terutama di perkantoran kepada pekerja dan sosialisasi tentang peragaan senam untuk meregangkan otot dan syaraf ketika bekerja di depan komputer.
\end{abstract}

Kata kunci : Keluhan, Postur Kerja, ROSA

\section{Pendahuluan}

PT. Universal Tekno Reksajaya adalah perusahaan yang bergerak dibidang remanufactur, general fabrikasi dan maintenance alat berat di Indonesia, perusahaan ini memiliki beberapa cabang/plant di Indonesia yaitu cabang Pekanbaru, Jakarta, Balikpapan, Sangata dan Timika, perusahaan ini juga memiliki subplant yang mensuport plant utama yaitu Pontianak, Banjarmasin, Adaro, Tanjung enim, Tanjung redep, dan Soroako.

PT. Universal Tekno Reksajaya memiliki beberapa divisi/bagian dalam lingkungan pekerjaannya, seperti bagian Administrasi, Marketing, produksi, service, dan warehouse.
Para pekerja di perusahaan ini memiliki tempat masing masing seperti mekanik yang bekerja di lapangan ataupun di workshop, dan para pekerja kantor yang bekerja di ruangan dan dalam pekerjaannya selalu menggunakan komputer, semua pekerja dalam pekerjaannya bekerja 8 jam /hari dan memungkinkan juga lebih jika diperlukan over time atau lembur.

PT. Universal Tekno Reksajaya plant Pekanbaru ini memiliki 2 lantai kantor, lantai pertama diisi oleh 9 orang pekerja dan lantai ke 2 diisi dengan 8 orang pekerja. Pada pelaksanaan Kerja praktek yang dilakukan di PT. Universal Tekno Reksajaya berada dibagian Administrasi dimana pada pelaksanaan kerjanya selalu didepan komputer. 
Pada saat survey awal ditemukan banyaknya keluhan yang dirasakan para pekerja kantor khusus nya 8 orang pekerja yang bekerja dilantai 2 , karena hal tersebut dibuatlah kuesioner tentang apa keluhan yang dirasakan pada pekerja kantor yang selalu bekerja didepan komputer, kuesioner dibuat untuk 8 orang pekerja kantor yang berada dilantai 2 yang selalu bekerja di depan komputer.

Dari kuesioner yang berikan dapat dilihat bayaknya keluhan pekerja yang dirasakan seperti pada punggung, pinggang, nyeri bahu, leher dan tangan. Keluhan yang dirasakan oleh pekerja kantor dapat diminimalkan dengan cara mengetahui dan mengidentifikasi postur kerja pada pekerja dalam menggunakan komputer. Identifikasi tersebut digunakan untuk mengetahui kondisi pekerja dan mengetahui penyebab keluhan yang dirasakan oleh pekerja untuk dilakukan perbaikan. Maka perlu dilakukan analisis dengan menggunakan metode Rapid office strain assessment (ROSA) untuk mengurangi adanya keluhan yang dirasakan oleh pekerja. ROSA merupakan salah satu metode pada office ergonomics, dimana penilaiannnya dirancang untuk mengukur resiko yang terkait dengan penggunaan komputer serta untuk menetapkan tingkat tindakan perubahan berdasarkan laporan dari ketidaknyamanan pekerja. Dengan menggunakan metode Rapid office strain assessment (ROSA), dapat diketahui apakah postur kerja karyawan kantor PT. Universal Tekno Teksajaya Plant Pekanbaru pada saat bekerja aman atau berbahaya.

\section{Methodologi}

Penelitian dilakukan pada bagian kantor di PT. Universal Tekno Reksajaya plant Pekanbaru. Objek yang diamati adalah para pekerja kantor yang bekerja di ruangan dan dalam pekerjaannya selalu menggunakan komputer, semua pekerja dalam pekerjaannya bekerja 8 jam/hari dan memungkinkan juga lebih jika diperlukan over time atau lembur.

Data yang digunakan dalam penelitian ini berawal dari data yang diperoleh dari pengamatan secara langsung, yaitu video dan foto postur kerja operator. Selanjutnya membagikan Standart Nordic Questionnaire $(S N Q)$ kepada para operator untuk mengidentifikasi keluhan rasa sakit, guna mengetahui masalah yang dialami oleh para pekerja pada saat bekerja secara terus menerus.

Tahap berikutnya melakukan penilaian postur kerja untuk semua aktivitas di bagian kantor. Penilaian dilakukan dengan menggunakan metode Rapid office strain assessment (ROSA).

\section{Hasil dan Pembahasan}

Beberapa kegiatan yang tidak alami para pekerja kantor di PT. Universal Tekno Reksajaya, sebagai berikut :

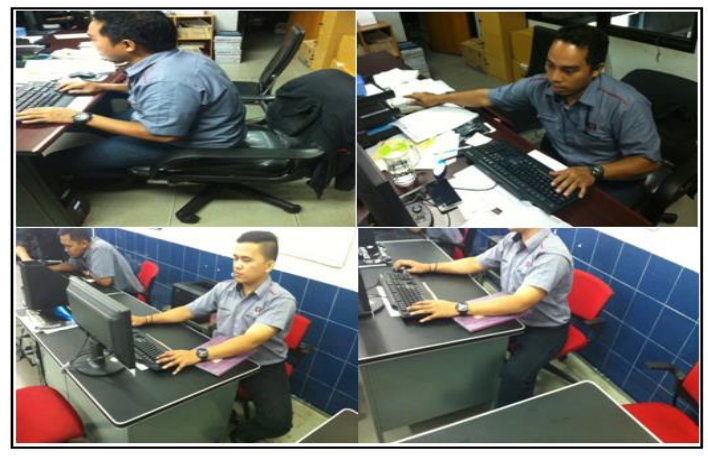

Gambar 1. Kondisi Riil di PT. Universal Tekno Reksajaya Plant Pekanbaru

Pada gambar diatas dapat dilihat kondisi kerja pekerja \& kondisi fasilitas kerja yang dipakai, seperti posisi kaki yang membentuk $<90^{\circ}$, sandaran tangan \& sandaran punggung yang terlalu kecil dan sandaran tangan \& punggung yang tidak bisa di adjustable.

\subsection{Identifikasi Keluhan Pekerja menggunakan Standard Nordic Questionnaire (SNQ)}

Untuk mengidentifikasi keluhan-keluhan yang dirasakan pekerja digunakan SNQ yang merupakan pertanyaan yang dilakukan secara langsung untuk mengetahui bagian tubuh mana yang sakit pada tubuh pekerja saat bekerja. Melalui kuesioner ini dapat diketahui bagian otot yang mengalami keluhan dengan tingkat keluhan mulai dari Tidak Sakit (A), Agak Sakit (B), Sakit (C) dan Sangat Sakit (D).

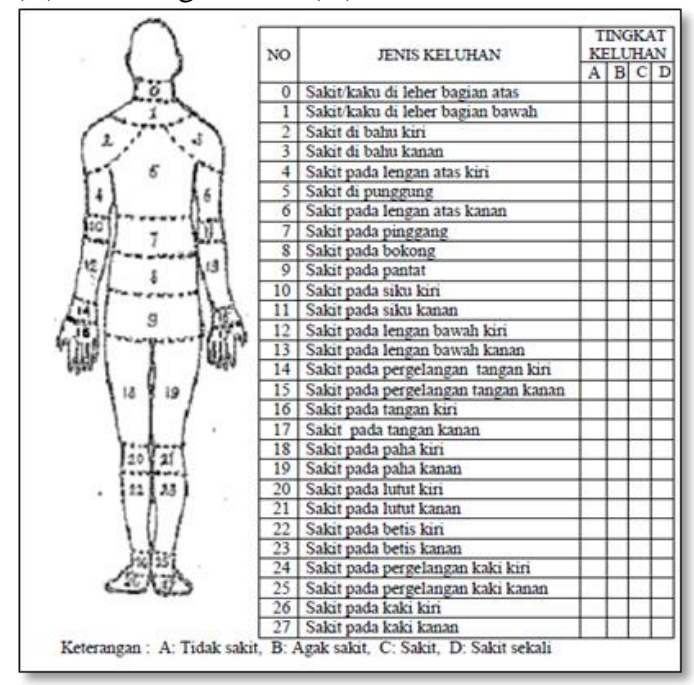

Gambar 2. Standard Nordic Questionnaire 
ISSN: 2354-6751

Dari hasil SNQ didapat bahwa pekerja merasakan sakit pada bagian sakit kaku dileher bagian, Kemudian sakit dileher bagian bawah, kemudian sakit pada pinggang.

\subsection{Penilaian Postur Kerja menggunakan metode ROSA}

Pengukuran postur kerja menggunakan metode ROSA yang dilakukan kepada 8 pekerja kantor didapat nilai yang telah direkapitulasi sebagai berikut :

\section{a. Data Ketinggian Kursi}

Tabel 1.

Rekapitulasi data ketinggian kursi

\begin{tabular}{|c|l|c|c|c|c|}
\hline No & \multicolumn{1}{|c|}{ Pekerja } & $\begin{array}{c}\text { sudut kaki yang } \\
\text { terbentuk }\end{array}$ & posisi kami dengan meja & $\begin{array}{c}\text { pengaturan } \\
\text { ketinggian kursi }\end{array}$ & skor \\
\hline 1 & Adm QA & $>90^{\circ}$ & Kaki tidak menyentuh meja & Adjustable & 2 \\
\hline 2 & Adm WIP/Support & $>90^{\circ}$ & Kaki tidak menyentuh meja & Adjustable & 2 \\
\hline 3 & PPC & $>90^{\circ}$ & Kaki tidak menyentuh meja & Adjustable & 2 \\
\hline 4 & SPV & $<90^{\circ}$ & Kaki tidak menyentuh meja & Adjustable & 2 \\
\hline 5 & COP Officer & $<90^{\circ}$ & Kaki tidak menyentuh meja & Adjustable & 2 \\
\hline 6 & Production support head & $<90^{\circ}$ & Kaki tidak menyentuh meja & Adjustable & 2 \\
\hline 7 & Adm Staff \& kasir & $>90^{\circ}$ & Kaki tidak menyentuh meja & Adjustable & 2 \\
\hline 8 & GA/IT \& Safety Officer & $>90^{\circ}$ & Kaki tidak menyentuh meja & Adjustable & 2 \\
\hline
\end{tabular}

\section{b. Data Kedalaman Kursi}

Tabel 2.

Rekapitulasi data ketinggian kursi

\begin{tabular}{|c|l|c|c|c|}
\hline No & \multicolumn{1}{|c|}{ Pekerja } & $\begin{array}{c}\text { Jarak ujuk kaki } \\
\text { dengan lutut }\end{array}$ & $\begin{array}{c}\text { pengaturan } \\
\text { kedalaman kursi }\end{array}$ & skor \\
\hline 1 & Adm QA & Lebih dari 3 inci & Non-Adjustable & 3 \\
\hline 2 & Adm WIP/Support & Lebih dari 3 inci & Non-Adjustable & 3 \\
\hline 3 & PPC & Sekitar 3 inci & Non-Adjustable & 2 \\
\hline 4 & SPV & Lebih dari 3 inci & Non-Adjustable & 3 \\
\hline 5 & COP Officer & Lebih dari 3 inci & Non-Adjustable & 3 \\
\hline 6 & Production support head & Lebih dari 3 inci & Non-Adjustable & 3 \\
\hline 7 & Adm Staff \& kasir & Lebih dari 3 inci & Non-Adjustable & 3 \\
\hline 8 & GA/IT \& Safety Officer & Lebih dari 3 inci & Non-Adjustable & 3 \\
\hline
\end{tabular}

c. Data Sandaran tangan

Tabel 3.

Rekapitulasi data Sandaran tangan

\begin{tabular}{|l|l|l|l|r|r|}
\hline \multicolumn{2}{|c|}{ Pekerja } & Posisi sandaran tangan & $\begin{array}{c}\text { lebar sandaran } \\
\text { tangan }\end{array}$ & $\begin{array}{c}\text { Pengaturan } \\
\text { sandaran tangan }\end{array}$ & skor \\
\hline 1 & Adm QA & Terlalu tinggi & Terlalu lebar & Non-Adjustable & 4 \\
\hline 2 & Adm WIP/Support & Mendukung & Terlalu lebar & Non-Adjustable & 3 \\
\hline 3 & PPC & Mendukung & Terlalu lebar & Non-Adjustable & 3 \\
\hline 4 & SPV & Mendukung & Terlalu lebar & Non-Adjustable & 3 \\
\hline 5 & COP 0fficer & Mendukung & Terlalu lebar & Non-Adjustable & 3 \\
\hline 6 & Production support head & Mendukung & Terlalu lebar & Non-Adjustable & 3 \\
\hline 7 & Adm Staff \& kasir & Mendukung & Terlalu lebar & Non-Adjustable & 3 \\
\hline 8 & GA/TT \& Safety Officer & Terlalu tinggi & Terlalu lebar & Non-Adjustable & 4 \\
\hline
\end{tabular}

\section{d. Data Sandaran punggung}

Tabel 4.

Rekapitulasi data Sandaran punggung

\begin{tabular}{|c|c|c|c|c|}
\hline Pekerja & $\begin{array}{c}\text { Posisis sandaran } \\
\text { punggung }\end{array}$ & $\begin{array}{c}\text { posisi permukaan } \\
\text { meja kerja }\end{array}$ & $\begin{array}{c}\text { pengaturan sandaran } \\
\text { punggung }\end{array}$ & sk \\
\hline Adm QA & Tidak Digunakan & Tidak Tinggi & Non-Adjustable & 3 \\
\hline 2 Adm WIP/Support & Memadai & Terlalu tinggi & Non-Adjustable & 3 \\
\hline 3 PPC & Tidak Digunakan & Tidak Tinggi & Non-Adjustable & 3 \\
\hline $4 \mathrm{SPV}$ & Tidak Digunakan & Terlalu tinggi & Non-Adjustable & 4 \\
\hline $5 \mid$ COP Officer & Tidak Digunakan & Terlalu tinggi & Non-Adjustable & 4 \\
\hline \begin{tabular}{l|l|l} 
Production support head \\
\end{tabular} & Tidak Digunakan & Terlalu tinggi & Non-Adjustable & 4 \\
\hline 7 Adm Staff \& kasir & Tidak Digunakan & Tidak Tinggi & Non-Adjustable & 3 \\
\hline 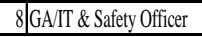 & Memadai & Terlalu tinggi & Non-Adjustable & 4 \\
\hline
\end{tabular}

\section{e. Data Penggunaan mouse}

Tabel 5.

Rekapitulasi data Penggunaan mouse

\begin{tabular}{|c|c|c|c|c|}
\hline Pekerja & posisi mouse & Letak molse & Durasi & skor \\
\hline $1 \mathrm{Adm} \mathrm{QA}$ & Mudah dijangkau & Satumeja dengan Keyboard & Leoih dari l jam \& kontinyu & 2 \\
\hline 2Adm WPISupport & Mudah dijangkalu & Satu meja dengan Keyboard & Lebih dari l jam \& kontinyu & 2 \\
\hline $3 \mid \mathrm{PC}$ & Mudah dijangkaul & Satu meja dengan Keyboard & Leoih dari l jam \& kontinyu & 2 \\
\hline 4 SPV & Mudah dijangkau \& Mousse terlalu kecil & Satu meja dengan Keyboard & Leoih dari l jam \& kontinyu & 3 \\
\hline 5) COPOfficer & Mudah dijangokau & Satu meja dengan Keyboard & Leoih dari l jam \& kontinyu & 2 \\
\hline 6 Production supporthead & Mudah dijangkau & Satu meja dengan Kejooard & Lebih dari l jam \& kontinyu & 2 \\
\hline 7 Adm Staff \& kasir & Mudad dijangkaul & Satu meja dengan Kejboard & Lebih dari l jam \& kontinyu & 2 \\
\hline 8 GAAlT' \& Safety Officer & Mudah dijangkaul & Satu meja dengan Keyboard & Lebih dari l jam \& kontinyul & 2 \\
\hline
\end{tabular}

\section{f. Data Pengunaan keyboard}

Tabel 6.

Rekapitulasi data Pengunaan keyboard

\begin{tabular}{|c|c|c|c|c|}
\hline Pekerja & $\begin{array}{c}\text { sudut yang } \\
\text { terbentuk tagan }\end{array}$ & Posisi Keyboard & Durasi & skor \\
\hline $1 \mathrm{Adm}$ QA & $>15^{\circ}$ & Tidak Tinggi & Lebih dari 1 jam \& kontinyu & 3 \\
\hline 2 Adm WIP/Support & $>15^{\circ}$ & Tidak Tinggi & Lebih dari 1 jam \& kontinyu & 3 \\
\hline $3 \mathrm{PPC}$ & $>15^{\circ}$ & Tidak Tinggi & Lebih dari 1 jam \& kontinyu & 3 \\
\hline 4 SPV & $>15^{\circ}$ & Keyboard terlalu tinggi & Lebih dari l jam \& kontinyu & 4 \\
\hline \begin{tabular}{l|l} 
5 COP Officer \\
\end{tabular} & $>15^{\circ}$ & Keyboard terlalu tinggi & Lebih dari 1 jam \& kontinyu & 4 \\
\hline \begin{tabular}{|l|l|}
6 Production support head \\
\end{tabular} & $>15^{\circ}$ & Keyboard terlalu tinggi & Lebih dari 1 jam \& kontinyu & 4 \\
\hline \begin{tabular}{l|l} 
Adm Staff \& kasir \\
\end{tabular} & $>15^{\circ}$ & Tidak Tinggi & Lebih dari 1 jam \& kontinyu & 3 \\
\hline 8 GA/T \& Safety Officer & $>15^{\circ}$ & Tidak Tinggi & Lebih dari 1 jam \& kontinyu & 3 \\
\hline
\end{tabular}

\section{g. Data Penggunaan monitor}

Tabel 7.

Rekapitulasi data Penggunaan monitor

\begin{tabular}{|l|l|c|c|c|c|c|}
\hline \multirow{2}{*}{ No } & \multicolumn{1}{|c|}{ Pekerja } & Posisi monitor & pencahayaan monitor & sandaran kertas & Durasi & skor \\
\hline 1 & Adm QA & Terlalu rendah & Cukup & Tidak ada & Lebih dari 1 jam \& kontinyu & 4 \\
\hline 2 & Adm WIP/Support & Terlalu tinggi & Cukup & Tidak ada & Lebih dari 1 jam \& kontinyu & 5 \\
\hline 3 & PPC & Terlalu rendah & Cukup & Tidak ada & Lebih dari 1 jam \& kontinyu & 4 \\
\hline 4 & SPV & Terlalu tinggi & Cukup & Tidak ada & Lebih dari 1 jam \& kontinyu & 5 \\
\hline 5 & COP Officer & leher memutar & Terlalu terang & Tidak ada & Lebih dari 1 jam \& kontinyu & 5 \\
\hline 6 & Production support head & sejajar & Terlalu terang & Tidak ada & Lebih dari 1 jam \& kontinyu & 4 \\
\hline 7 & Adm Staff \& kasir & sejajar & Terlalu terang & Tidak ada & Lebih dari 1 jam \& kontinyu & 4 \\
\hline 8 & GA/T \& Safety Officer & sejajar & Terlalu terang & Tidak ada & Lebih dari 1 jam \& kontinyu & 4 \\
\hline
\end{tabular}


h. Data Penggunaan telephone

Tabel 8.

Rekapitulasi data Penggunaan telephone

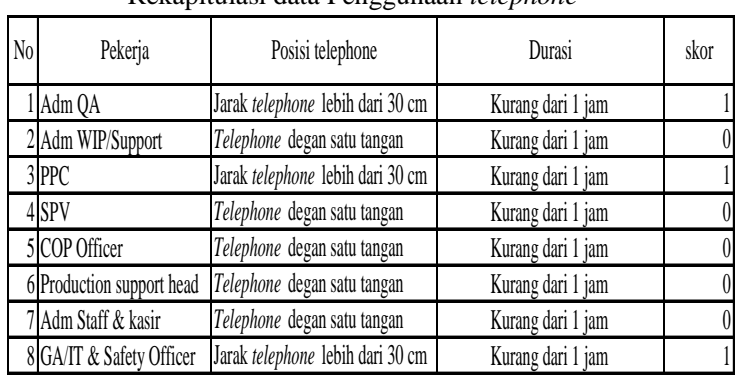

\subsection{Penentuan Nilai akhir Menggunakan Metode ROSA}

Penentuan nilai akhir dilakukan dengan menggunakan data yang telah dikumpulkan pada tahapan sebelumnya, dari tahapan tersebut kemudian dinilai sesuai dengan kriteria yang ada pada lembar penilaian ROSA, penilain mengunakan metode ROSA dibagi menjadi 3 bagian yaitu Bagian A (kursi), Bagian B (monitor dan telephone), dan Bagian $\mathrm{C}$ (mouse dan keyboard). sebelum penentuan nilai akhir terdapat beberapa tahapan yang dilakukan yaitu menentukan skor Bagian A, skor bagian B, skor Bagian C, pirepheral skor, dan nilai akhir, berikut adalah tahapan menentukan nilai skor dengan metode ROSA.

\section{(1). Menentukan Nilai Skor Bagian A}

Menentukan nilai skor bagian A yaitu dengan cara membandingkan antara ketinggian kursi + kedalaman kursi dengan sandaran tangan + sandaran punggung dengan menggunakan Log Up Table. Berikut adalah perhitungan dari tahapan penentuan nilai akhir bagian A dari ke 8 pekerja.

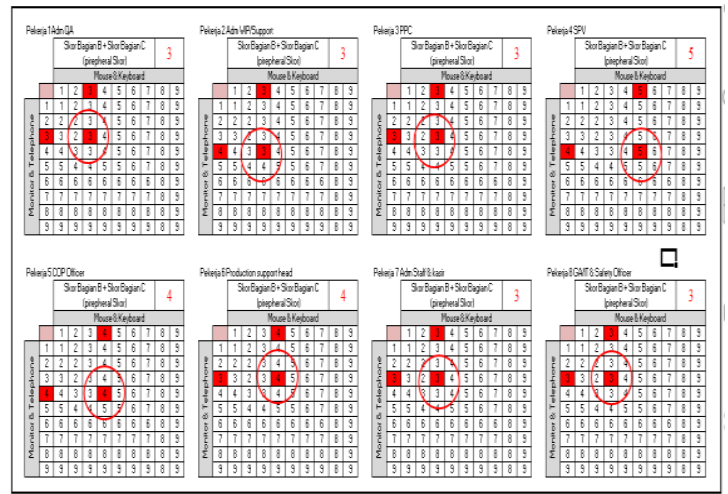

Gambar 3. Perhitungan Nilai Akhir bagian A

\section{(2). Menentukan Nilai Skor Bagian B}

Menentukan nilai skor bagian B yaitu dengan cara membandingkan antara Monitor dengan Telephone dengan menggunakan Log Up Table. Berikut adalah adalah perhitungan dari tahapan penentuan nilai akhir bagian $\mathrm{B}$ dari ke 8 pekerja.

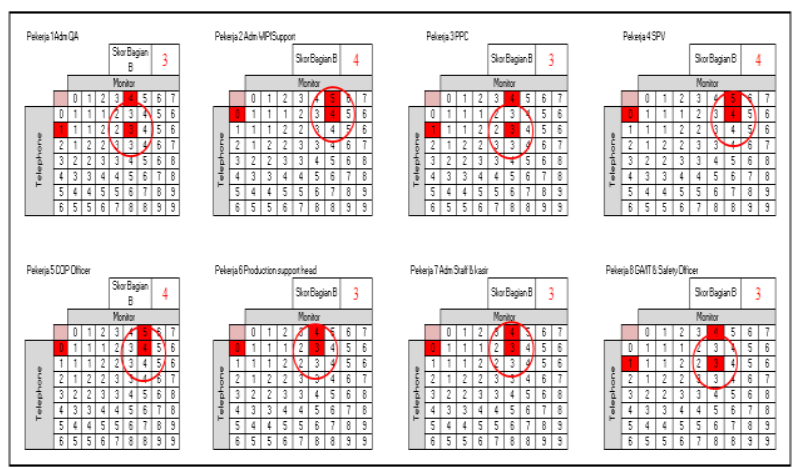

Gambar 4. Perhitungan Nilai Akhir bagian B

\section{(3). Menentukan Nilai Skor Bagian C}

Menentukan nilai skor bagian A yaitu dengan cara membandingkan antara ketinggian Keyboard dengan Mouse dengan menggunakan Log Up Table, Berikut adalah adalah perhitungan dari tahapan penentuan nilai akhir bagian $\mathrm{C}$ dari ke 8 pekerja.

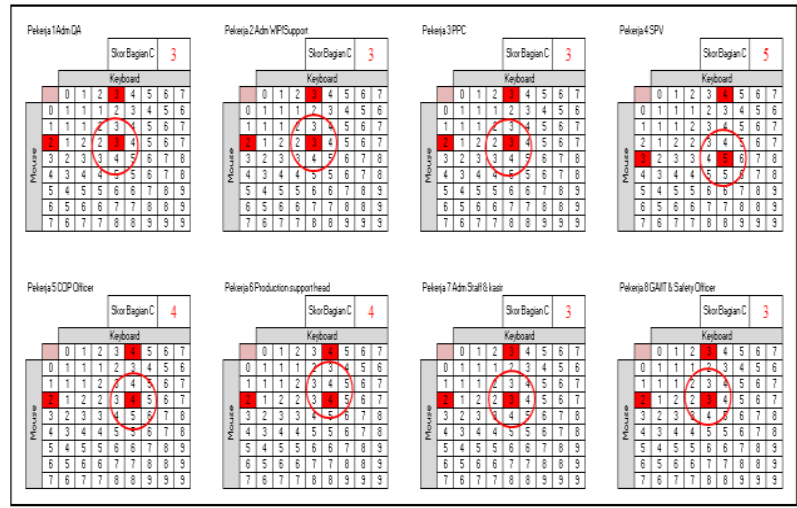

Gambar 5. Perhitungan Nilai Akhir bagian C

\section{(4).Menentukan Nilai Bagian Pirepheral Skor}

Menentukan nilai skor bagian A yaitu dengan cara membandingkan antara Mouse + Keyboard dengan Monitor + Telephone dengan menggunakan Log Up Table. Berikut adalah adalah perhitungan dari tahapan penentuan nilai akhir bagian Pirepheral dari ke 8 pekerja. 


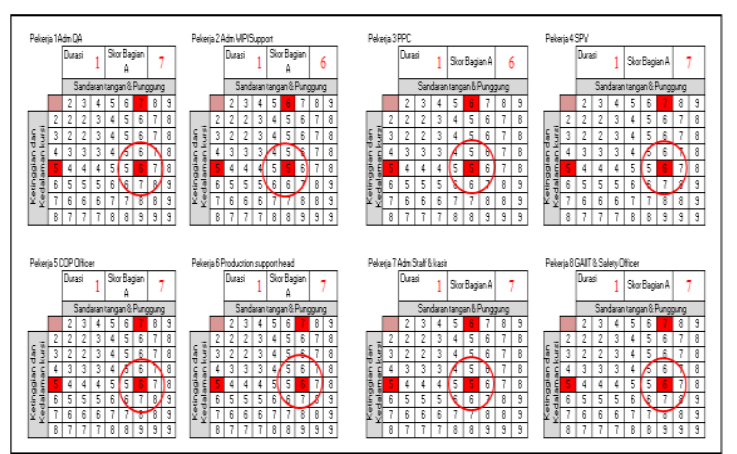

Gambar 6. Perhitungan Nilai Akhir bagian Pirepheral

(5). Menentukan Nilai Skor Akhir ROSA

Menentukan nilai skor akhir ROSA yaitu dengan cara membandingkan antara nilai Pirepheral Skor dengan Kursi dengan menggunakan Log Up Table, Berikut adalah tahapan penentuan nilai skor akhir ROSA.

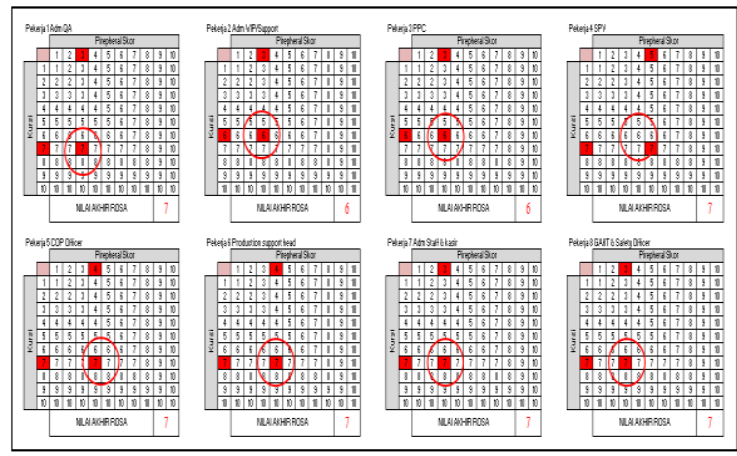

Gambar 7. Perhitungan Nilai Skor Akhir ROSA

\section{(6). Klasifikasi Tingkat Resiko}

Setelah didapatkan hasil akhir dari data pengolahan dari setiap sampel dilakukan tahap klasifikasi resiko berdasarkan hasil pengukuran, nilai tersebut kemudian diklasifikasikan kembali untuk menentukan apakah postur kerja tersebut beresiko atau tidak. Apabila nilai akhir yang diperoleh lebih dari lima makan postur kerja tersebut dianggap beresiko sedangkan apabila nilai akhir yang diperoleh kurang dari lima dianggap tidak beresiko/berbahaya, berikut adalah table klasifikasi nilai akhir yang diperoleh dari sampel yang diambil.

Tabel 9.

Tabel Klasifikasi Tingkat Resiko

\begin{tabular}{|c|l|c|c|}
\hline No & \multicolumn{1}{|c|}{ Pekerja } & Nilai & Resiko \\
\hline 1 & Adm QA & 7 & beresiko \\
\hline 2 & Adm WIP/Support & 6 & beresiko \\
\hline 3 & PPC & 6 & beresiko \\
\hline 4 & SPV & 7 & beresiko \\
\hline 5 & COP Officer & 7 & beresiko \\
\hline 6 & Production support head & 7 & beresiko \\
\hline 7 & Adm Staff \& kasir & 7 & beresiko \\
\hline 8 & GA/IT \& Safety Officer & 7 & beresiko \\
\hline
\end{tabular}

\section{Simpulan}

Dari penelitian yang dilakukan dapat disimpulkan bahwa :

1. Keluhan yang tertinggi yang dirasakan pekerja kantor PT Universal Tekno Reksajaya Plant Pekanbaru terdapat pada bagian sakit kaku dileher bagian, Kemudian sakit dileher bagian bawah, kemudian sakit pada pinggang.

2. Penilaian postur kerja dengan metode ROSA menunjukkan bahwa seluruh pekerja beresiko tinggi dan harus dikaji lebih lanjut, dari analisa tersebut diperoleh:

a. Pekerja 1 (Adm QA) memperoleh nilai 7.

b. Pekerja 2 (Adm WIP/Support) memperoleh nilai 6 .

c. Pekerja 3 (PPC) memperoleh nilai 6.

d. Pekerja 4 (SPV) memperoleh nilai 7.

e. Pekerja 5 (COP Officer) memperoleh nilai 7.

f. Pekerja 6 (Production support head) memperoleh nilai 7.

g. Pekerja 7 (Adm Staff dan kasir ) memperoleh nilai 7 .

h. Pekerja 8 (GA/IT dan Safety Officer) memperoleh nilai 7 .

Dimana apabila nilai akhir yang diperoleh lebih dari lima makan postur kerja tersebut dianggap beresiko sedangkan apabila nilai akhir yang diperoleh kurang dari lima dianggap tidak beresiko/berbahaya.

Dikarenakan kondisi tersebut perlu direkomendasikan kepada pihak perusahaan agar memberikan pelatihan tentang ergonomi terutama di perkantoran kepada pekerja dan sosialisasi peragaan senam untuk meregangkan otot dan syaraf ketika bekerja didepan komputer

\section{Daftar Pustaka}

[1] Manuaba, A. 1992. Pengaruh Ergonomi Terhadap Produktivitas Tenaga Kerja. Seminar Produktivitas Tenaga Kerja Di Jakarta, Pada tanggal 30 Januari 1992.

[2] Maryati, Analisa Postur kerja Karyawan PT. Tiga Serangkai Department Publishing Dengan menggunakan Metode ROSA (Rapid Office Strain Assesment), Universitas Negeri Semarang, 2014.

[3] Sonne, M.W.L., Villalta, D.L., and Andrews, D.M, Development and Evaluation of an Office Ergonomic Risk Checklist: The Rapid Office Strain Assessment (ROSA). Applied Ergonomics 43(1), 2012:98-108. 
ISSN: 2354-6751

[4] Sutalaksana, I. Z. Produk-Produk Ergonomis dan Strategi Mewujudkanya. Dalam; Proceedings Simposium dan Pameran Ergonomic Indonesia 2000, Tehnology Business Operation Unit IPTN, Bandung I, 1999 : 19-24.

[5] Sutalaksana, I. Z, Anggawisastra, R, dan Tjakraatmadja, J. H, Teknik Tata Cara Kerja, Departemen Teknik Industri ITB, Bandung, 1979.
[6] Tarwaka, Solichul, dkk. Ergonomi untuk Keselamatan, Kesehatan Kerja dan Produktivitas. Denpasar: Universitas Udayana. 2004.

[7] Zayyinul Hayati Zen, Perancangan Alat Material Handling Dengan Menggunakan Pendekatan Biomekanika dan Postur Kerja pada Bagian Pengepakan Pupuk di CV. Bukit Raya Laendrys Bukittinggi, Universitas Muhammadiyah Riau. 2014 